\title{
O questionamento de Nietzsche ${ }^{*}$
}

\author{
Paul van Tongeren**
}

\begin{abstract}
Resumo: Quando Nietzsche é chamado de um filósofo radical, é (dentre outras razões) porque pretende pôr em questão o que outros pensadores tomam por certo. No artigo, concentro-me no modo pelo qual Nietzsche pergunta suas questões e em como elas (e o vocabulário que utiliza para expressá-las) se desenvolvem ao longo de seus escritos. $\mathrm{O}$ artigo aponta como Nietzsche gradativamente descobre suas questões adequadas e como essa busca atinge seu clímax por volta de 1886. Essa questão adequada se torna uma questão prática ou existencial: "Em que medida a verdade pode suportar a incorporação?" (FW/GC 110, KSA 3.471).
\end{abstract} Palavras-chaves: questão- tarefa - desenvolvimento de Nietzsche

\section{Introdução}

H.-G. Gadamer cita com aprovação a tese de R.G. Collingwood de que compreender um texto significa compreender a questão à qual o texto quer dar uma resposta ${ }^{1}$. A hermenêutica sabe que essa questão geralmente não é simplesmente "dada", mas tem que ser apresentada através de uma interpretação do texto. Não quero discutir agora o problema que Gadamer aponta com o conceito de "Vorgriff der Vollkommenheit"2. Quero apenas fazer uma pergunta

\footnotetext{
* Tradução de André Luiz Fávero.

** Professor da Universidade Radboud Nijmegen, Nijmegen, Holanda, e da Universidade de Leuven, Bélgica. Coordenador do Nietzsche Research Group e um dos editores do NietzscheWörterbuch. Uma versão estendida do texto foi publicada em holandês em Tijdschrift voor Filosofie 70 (2008) 3, p. 427-451.
}

1 GADAMER, H.-G. Wahrheit und Methode. Grundzüge einer philosophischen Hermeneutik. Tübingen: Mohr, 1975, p. 352.

2 Idem, ibidem, p. 277 e segs. 
mais ingênua: não é estranho que a questão possa ser descoberta apenas pela resposta? Ela não deveria preceder a resposta que recebe? Por que a questão não está simplesmente no início do texto? Como poderia a res-posta preceder aquilo a que ela responde? Como poderia aquilo que vem depois ser anterior ao que vem antes?

Deve ser não apenas verdadeiro acerca de um texto que ele só possa ser entendido compreendendo a questão à qual ele dá uma resposta; ele deve ser sustentado, em geral, por uma filosofia. Se queremos compreender um filósofo, devemos compreender qual é a questão que o ocupa. Pois não assumimos que o pensamento se origina de questões? Que ele é motivado e movido por questões? Mas se tentamos marcar cuidadosamente essa questão original e "originante" de um pensador, teremos que estudar sua obra. Muito raramente encontraremos aquela questão simplesmente no início da primeira página do primeiro livro. E, se a encontrássemos lá, compreendê-la-íamos somente com a leitura do que se segue. Por que assim o é? É apenas o leitor que necessita da resposta para compreender a questão? $\mathrm{O}$ autor sabe o que significa a questão antes de dar a resposta?

Concentrar-me-ei em um filósofo, Nietzsche, e em suas questões. O que podemos aprender de Nietzsche sobre o papel do questionamento em filosofia? Nietzsche é um modelo de questionador? Há uma verdadeira questão na origem de seu pensamento? Como são as questões e os pontos de interrogação de Nietzsche?

\section{As "palavras-questões" e os pontos de interrogação de Nietzsche}

Depois desse embaraço filosófico sobre questões e como elas produzem ou originam textos, descerei primeiramente ao mais fundo de uma aproximação filológica. Como foi explicado na primeira contribuição para esta discussão, estamos trabalhando no projeto de composição de um Nietzsche-Wörterbuch, para a qual estou preparando uma entrada ao lema "Frage/fragwürdig". Nosso 
Dicionário Nietzsche assume primordialmente uma aproximação semiótica, o que significa que assumimos como ponto de partida para nossa pesquisa a palavra no sentido de significante, mais do que de conceito. Neste caso, ela significa que eu em primeiro lugar me concentro no uso, por Nietzsche, da palavra "Frage" e naquelas palavras em que reconhecemos aquela palavra. Somente secundariamente olharei também para os pronomes interrogativos ("Wo", "wann", "wer", "warum", "wie", "was", "womit" e muitos mais) e para os pontos de interrogação que Nietzsche escreve.

Todas as palavras-questões (quero dizer apenas aquelas palavras nas quais a raiz "Frag" pode ser encontrada, não os pronomes interrogativos nem as palavras do campo semântico como "Problem", "Rätsel", "Zweifel", "Antwort", "Suchen", "Versuchen", etc.) ocorrem todas elas juntas mais de 1550 vezes. Se contarmos todos os pontos de interrogação, temos mais de 8200. Claro, estes números não dizem muito. Alguém teria que os relacionar ao número de páginas e comparar essa relação a outros autores. Mas, dito isso, podemos dizer que os números sejam de fato grandes. Sem dúvida Nietzsche pertence, junto com autores como Platão e Santo Agostinho, àqueles que muito frequentemente utilizam pontos de interrogação e fazem perguntas.

Certamente temos de admitir que não encontramos qualquer filosofia explícita do questionar em Nietzsche, nenhuma teoria mais ou menos elaborada sobre o que seja uma questão, como elas se originam ou como funcionam. Sequer dificilmente há qualquer aforismo no qual algo seja dito "sobre" questões tais quais, sem falar qualquer coisa espetacular. Portanto, não buscarei uma teoria nietzschiana da questão, mas examinarei o real uso, por Nietzsche, da palavra "Frage" e palavras relacionadas, e perguntarei se isso pode nos dizer algo sobre o papel e significado das questões em filosofia. Descreverei alguns de seus escritos nos termos de suas características-de-questões e então exprimirei uma conclusão muito provisória sobre o desenvolvimento de Nietzsche e sobre a relação entre uma filosofia e sua questão. 
Van Tongeren, P.

\section{Uma História do Desenvolvimento das Questões de Nietzsche}

\subsection{O nascimento da tragédia}

Se alguém começa a ler bem no início dos escritos de Nietzsche supõe imediatamente que seja vantajoso estudar o desenvolvimento das questões de Nietzsche. O primeiro texto no qual de fato está a edição padrão (quero dizer a Kritische Studienausgabe) é - claro - o primeiro texto que Nietzsche publicou depois de ter aceitado seu magistério na Basileia: $O$ nascimento da tragédia no Espírito da Música, de 1872. O volume abre, todavia, com o novo prefácio ao texto, que Nietzsche adicionou à sua segunda edição em 1886. $\mathrm{E}$ o leitor imediatamente nota que muito fora modificado naqueles 14 anos. Permita-me começar quantitativamente: no prefácio original (1872), que tem apenas 2 páginas, não encontramos qualquer palavra-questão (à parte do "problema estético" que ele quer seriamente tratar) e nenhum ponto de interrogação. No novo prefácio (que tem 12 páginas) encontramos 18 palavras-questões, 10 palavras-problemas e 74 pontos de interrogação. Claro que é importante reconhecer que o prefácio original fora uma dedicatória a Richard Wagner, ao passo que o prefácio posterior foi um "Esforço de uma Autocrítica". Mas isso não explica completamente a enorme diferença. Ao contrário, podemos dizer que de modo geral Nietzsche, gradualmente, no decurso de seus escritos, faz mais questões e utiliza ainda mais frequentemente palavras-questões. Ao menos até meados de 1880 quando esse desenvolvimento parece atingir seu clímax.

Uma outra notável, mas ainda externa, diferença entre $O$ nascimento da tragédia e seu prefácio posteriormente adicionado é o vocabulário-questão em si. No livro encontramos quase somente a palavra "fragen", poucas vezes "sich fragen" e "befragen", mas nenhum ulterior composto que Nietzsche formará mais tarde, nem quaisquer adjetivos com os quais depois ele especificará suas questões e os quais indicará que ele atenta sim para a natureza de 
seu questionar. A única exceção é a palavra favorita de Nietzsche "fragwürdig", mas no texto inicial esta significa simplesmente "questionável"; ela indica algo que levanta questões, e é usada para coisas acerca das quais o autor tem algo a dizer. De acordo com O nascimento da tragédia, três "coisas" são "fragwürdig" (o tratamento de Eurípides do mito, o caráter de Sócrates e nossa cultura contemporânea). Em todos estes três casos é obvio que as questões que são levantadas por esses "assuntos" problemáticos não são de fato verdadeiras questões. $\mathrm{O}$ autor tem fortes opiniões sobre esses assuntos, os quais parcialmente declara sob a aparência de "questões". A meu ver, é altamente questionável se quaisquer questões verdadeiras de fato são feitas em $O$ nascimento da tragédia. A maioria das questões que encontramos claramente servem como instrumentos literários para continuar o discurso e mantê-lo estruturado.

No prefácio posterior vemos quase o oposto. Imediatamente na primeiríssima linha do texto Nietzsche utiliza a palavra "fragwürdig", questionável, e a reporta não a algo sobre o qual escreve, mas a seu próprio livro: "O que quer que esteja no fundo deste questionável livro, deve ser uma questão excepcionalmente significativa e fascinante, e profundamente pessoal". O livro é chamado questionável porque surge de questões excepcionalmente significativas, fascinantes e pessoais. No restante do texto essas questões são diferenciadas - ele distingue questões pessoais, psicológicas, fisiológicas e psiquiátricas, questões de classificação diferente, graves questões ("schwere Fragen"), questões fundamentais ("Grundfrage") etc. E isso indica uma outra característica que será confirmada no restante de seus escritos: seu vocabulário-questão tornar-se-á ainda mais diferenciado, novamente até meados de 1880.

Mas o que é mais importante: no texto posterior as questões são explicitamente perguntadas e Nietzsche esclarece que ele somente então reconhece a seriedade do problema a que se dedicou 14 anos antes. A intenção do prefácio parece ser que o autor quer esclarecer 
Van Tongeren, $\mathrm{P}$.

que 14 anos antes ele tivera muito mais questões e muito mais questões importantes do que ele mesmo percebia naquele tempo. Deixem-me retornar, portanto, à ordem cronológica e resumir brevemente como essa diferença se desenvolve.

\subsection{As considerações extemporâneas}

Nas Considerações extemporâneas encontramos a respeito das questões principalmente duas coisas. A primeira delas é mais ou menos a mesma de $O$ nascimento da tragédia: Nietzsche utiliza questões como ferramentas estilísticas ou como um instrumento retórico. Ele compõe seu "argumento" com a ajuda de questões; na introdução ele anuncia quais questões devem ser feitas, estrutura-o com a ajuda dessas questões e regularmente se reporta de novo às questões para orientar a atenção do leitor. Um exemplo da primeira Consideração Extemporânea: no final da introdução Nietzsche menciona as questões com as quais lidará: "nada desejamos [...] a não ser uma resposta honesta a três questões. Primeira: como o novo crente concebe seu céu? Segunda: qual é o tamanho da coragem com a qual esses novos crentes o produzem? E terceira: como ele escreve seu livro?" (DS/Co Ext. I 4, KSA 1.177).

Mas estas questões de fato não indicam do que o texto realmente se trata. Elas são apenas as ferramentas com a ajuda das quais uma estrutura é dada ao discurso que na verdade versa sobre outras questões. Nietzsche quer sim trazer à baila outras questões, isto é, questões sobre o sentido da vida, isto é: a vida da cultura, mas principalmente a vida do indivíduo. Questões como: "por que e para qual propósito as pessoas vivem?" e "se [você] gostaria de reviver os últimos dez ou vinte anos" (HL/Co Ext. II 1, KSA 1.255), "a questão: 'de que valor é de fato a vida?' [...] 'você afirma sua existência do fundo de seu coração" (SE/Co Ext. III 3, KSA 1.363), "a questão: "qual é o propósito de sua vida?"“" (SE/Co Ext. III.4 KSA 1.374), “a questão [...] como pode sua vida, a vida de um 
indivíduo, obter o valor mais alto, a importância mais profunda? Como ela é menos desperdiçada?" (SE/Co Ext. III.6 KSA 1.384), "apenas se pergunte por que você, como um indivíduo, existe" (HL/ Co Ext.II 9, KSA 1.319 UO). Nietzsche quer concentrar sua atenção em questões como estas, mas o faz num discurso que está sendo estruturado por outras questões. As questões que ele se pergunta são diferentes daquelas que apresenta como sendo as importantes. Ele proclama as questões importantes mas não as pratica. Temos a impressão de que a disparidade que caracterizou a vida de Nietzsche quando era um professor na Basileia, embora quisesse ser um médico ou educador filosófico, esteja sendo espelhada no vocabulário-questão que ele utiliza.

Suponho que o questionar de Nietzsche encontre sua própria forma somente nos escritos aforísticos da próxima fase de sua vida. As diferenças entre os sucessivos livros aforísticos de Humano, demasiado humano até e incluindo a primeira edição de $A$ gaia ciência são pequenas. Tentaremos apontar algumas características por livro, mas todos eles realmente ocupam todo o período entre 1878 e 1882.

\subsection{Humano, demasiado humano}

No primeiro volume de Humano, demasiado humano vemos o questionamento de Nietzsche se tornando mais e mais imperioso sobre si próprio. Até então era ele quem colocava e apresentava as questões, mas de agora em diante ele parece se tornar obediente a um questionar que se lhe impõe com insistência, ou a alguma coisa em si próprio que lhe impinge questões. Ele percebe uma "inclinação" sobre si, a qual o força a fazer perguntas, uma inclinação para o que alguém "deve [...] ser quase inumano" (MA I 1, KSA 2.24); não é ele próprio mas "a mente" que pergunta (MA I 13, KSA 2.34), ou "nossos sentidos" (MA I/HH I 217, KSA 2.177); "a ciência" ela mesma "pergunta depois da origem e da 
história das assim chamadas sensações morais" (MA I/HH I 37, KSA 2.59). Se é o autor mesmo que coloca as questões, elas são muito menos retóricas. Anteriormente suas questões eram mais "primeiros passos" para capacitá-lo a dar sua própria resposta. Mas de agora em diante o encontramos levantando questões, ou enfrentando questões que ele não responde.

Às vezes é como se ele não estivesse sequer apto a exprimir a questão que sente pressioná-lo: "Uma questão parece oprimir nossa língua e ainda se recusa a ser pronunciada", a questão que todavia é expressa como: "se alguém poderia conscientemente repousar na inverdade?" (MA I/HH I 34, KSA 2.53 e segs.).

Conspicuamente vemos com frequência de agora em diante que seus aforismos resultam em questões, muito frequentemente sem que essas questões sejam retóricas no sentido comum da palavra. A natureza imperiosa dessas questões a partir de então também as faz mais agourentas ou ameaçadoras. Ele fala de uma "questão terrível" ("schauderhafte Frage" MA I/HH I 55, KSA 2.74), ou de "a visão cruel" ("grausame Anblick" MA I/HH I 37, KSA 2.59) da investigação obrigada. Desse modo está longe do óbvio se seu questionar será para sua vantagem ou bem-estar: "nossa filosofia não se tornará assim uma tragédia? A verdade não se tornará hostil à vida [...]?" (MA I/HH I 34, KSA 2.53f) Em vez de ser o dirigente de seu questionamento, o pensador responde ao clamor de questões que ouve dentro de si mesmo. Um impressionante sintoma disso é o número de aforismos escritos na forma de um diálogo, que encontramos especialmente a partir do segundo volume de Humano, demasiado humano. O título dessa segunda parte é revelador: "O andarilho e sua sombra". Em muitos desses textos dialógicos o pensador se interroga, e a maioria desses questões estão longe de serem retóricas.

O pensador não está mais no controle de questões que de lá surgem. Ele que se sabe obrigado a questionar se torna uma questão para si próprio. É exatamente o que vemos acontecer mais e mais de agora em diante: as questões dizem respeito ao 
próprio questionamento do pensador. Um bom exemplo é a seção 43 de "O andarilho":

O pensador, entretanto, considerara tudo como tendo evoluído e tudo que evoluiu como discutível, e é, dessa maneira, um homem sem um senso de dever - ou seja, tanto quanto ele opera como um pensador. Assim, ele então fracassa em sentir um senso de dever no que diz respeito a ver e a dizer a verdade, e não reconhecerá qualquer desse dever; ele pergunta de onde isso vem? Qual é o seu propósito? - mas estas mesmas questões ele tomará como questionáveis [...] À medida que aqui o elemento exigido para aquecer a máquina parece ser o mesmo elemento que é para ser investigado por meio da máquina. (WS/ AS 43, KSA 2.572 e segs).

\subsection{Crepúsculo dos ídolos}

Esse traço apenas se tornará mais forte nos escritos seguintes. A interrogação apaixonada do pensar próprio de alguém percebe um conflito interior, e é em consequência profundamente problemático. No último prefácio adicionado ao Crepúsculo dos ídolos, Nietzsche escreve que esse livro começa corroendo a moral. $\mathrm{Na}$ verdade, ele havia começado a fazê-lo já antes. Mas esse livro realmente traz a natureza existencial de sua autoinvestigação, assim como sua conexão com a demolição da moral com maior força e disposição. Essa autoinvestigação ou, para ser mais preciso, essa investigação de sua própria investigação, esse questionar seu questionar, essa "paixão pelo conhecimento", essas "questões de verdade mais pessoais". - "O que estou realmente fazendo? E por que o faço?" (M/A 196, KSA 3.170), essa interrogação suspeita (cf. M/A 523, KSA 3.301) de seu próprio questionar apresenta-se mais claramente ser ela mesma dirigida por comandos morais (cf. M/A 61, KSA 3.61). E esse traço moral de sua autoinvestigação tornarse-á mais e mais problemático. 


\subsection{A gaia ciência}

A Gaia Ciência enfatiza ainda mais que a relação apaixonada do questionador com seu próprio questionar, essa "Leidenschaft der Erkenntniss", é uma relação moral. Mas essa paixão, não obstante, é uma ameaça à vida. Quem quer que procure a verdade combaterá toda falsidade, até mesmo quando as mentiras forem agradáveis ou mesmo necessárias à vida. $\mathrm{O}$ pensador (isto é, o questionador) apresenta a arena na qual a paixão pela vida e a paixão pelo conhecimento lutam uma contra a outra.

O pensador está agora sendo aquele no qual o impulso à verdade e aqueles erros preservadores-da-vida colidem em sua primeira luta, depois que o impulso à verdade provou ser também um poder preservador-da-vida. Comparado à significância dessa luta, tudo o mais se trata de indiferença: a derradeira questão sobre as condições de vida é aqui posta, e nos confrontamos com a primeira tentativa de responder a essa questão pela experiência. Em que medida a verdade pode suportar a incorporação? Eis a questão, eis a experiência. (FW/ GC 110, KSA 3.471).

3.6 Os escritos de 1886 (FW/GC Livro V e os novos prefácios)

Nesta breve visão geral omito Assim falava Zaratustra. Não somente porque em nosso trabalho para o Nietzsche Wörterbuch encontramos tempo e, novamente, que este livro é de uma natureza completamente diferente do resto dos escritos de Nietzsche, mas também porque em termos de questões e pontos de interrogação ele definitivamente não é um avanço no desenvolvimento esboçado, mas sim um retrocesso. Embora o livro tenha muitos pontos de interrogação, Nietzsche dificilmente faz verdadeiras questões, mas antes utiliza palavras-questões e pontos de interrogação numa

64 | cadernos Nietzsche 31, 2012 
forma retórica. Mas Zaratustra apenas interrompe e certamente não para o desenvolvimento indicado.

Se contarmos o novo prefácio que Nietzsche adicionou em 1886 à segunda edição de seu livro anterior, assim como o quinto livro de A gaia ciência, o qual ele também adicionou por volta de então, se contarmos separadamente cada um desses textos que Nietzsche escreveu imediatamente depois de Zaratustra, eles têm relativamente mais pontos de interrogação do que qualquer outro escrito de Nietzsche. Obviamente, chegamos a um ponto que é extremamente importante para o desenvolvimento da questão na filosofia de Nietzsche.

Nas primeiras poucas seções do quinto livro de $A$ gaia ciência Nietzsche resume sua filosofia em quatro questões, aludindo ao resumo da filosofia de Kant em $3+1$ questões: "was kann ich wissen?", "was soll ich tun?", e "was darf ich hoffen?"3 , resumidas em sua Logik como: "was ist der Mensch?"4. Deixem-me citar os títulos das seções de Nietzsche: $§ 343$, “O significado de nossas alegrias" lida com a religião e as consequências da morte de Deus; § 344: "Como nós, também, ainda somos piedosos" lida com o conhecimento e a busca pela verdade; $§ 345$ "Moral como um problema" lida, é claro, com a moral, e finalmente o $\$ 346$ conclui suas séries com um resumo sob o título: "Nosso ponto de interrogação". O pensador que tenha interrogado de modo tão completo quanto possível cada crença (religião), cada prática (moral) e cada conhecimento termina sendo confrontado com suas próprias questões e descobre que religião, moral e veracidade sobreviveram precisamente nestas questões: "não há dúvida que um 'tu deves' ainda fala a nós também, que também nós ainda obedecemos a uma rígida lei posta sobre nós" (M/A Prefácio 4,

3 KANT, I. Kritik der reinen Vernunft. Leipzig: Meiner, 2010, A 805/B 833.

4 KANT, I. Logik. Leipzig: Meiner, 1904, p.27. 
KSA 3.3.16). Ele termina encontrando a si mesmo como um ponto de interrogação: unser Fragezeichen.

Se os novos prefácios às vezes podem soar autoconfiantes e sugerir que o autor tenha superado um problema, isso não deveria nos desencaminhar. Nietzsche fala sim sobre uma vitória, mas a chama de "uma vitória questionável, apinhada-de-questões, enigmática" (MA/HH I Prefácio 3, KSA 2.16). Não uma vitória que deixa o problema pra trás, mas antes uma que finalmente o admite, até o procura: "Com essa vontade no coração alguém não tem medo do temível e do questionável que caracteriza toda existência; alguém até o persegue." (MA/HH II Prefácio 7, KSA 2.376f). Quem quer que seja vitorioso dessa maneira, não superou suas questões dando respostas definitivas a elas. Ao contrário, dessa vitória "alguém emerge (...) com um pouco mais de pontos de interrogação - sobretudo com a vontade de doravante questionar além, mais profundamente, mais severamente, mais asperamente, mais malvadamente, mais quietamente do que alguém antes já tenha questionado" .

\section{Conclusão}

Uma análise cuidadosa dos escritos, de Para a genealogia da moral em diante mostraria que Nietzsche a partir de então, não mais desenvolve sua questão para além, mas antes "percebe" ou "desempenha" a questão que ele "tem se tornado" ("wer sind wir eigentlich?" GM/GM Prefácio 1, KSA 5.247) de modo ainda mais extremo. Não posso elaborar essa análise aqui e agora, mas tento concluir, embora prematuramente, em dois pontos:

\subsection{O desenvolvimento de Nietzsche "para" sua questão}

Descobrimos que o questionamento de Nietzsche se desenvolve como sendo uma técnica com a qual ele apresenta suas proposições 
num discurso bem estruturado, via uma outra técnica retórica com a ajuda da qual ele tenta convencer seus leitores acerca da importância de certas questões, e via uma ainda mais suspeita interrogação da moral, da fé e do conhecimento, e enfim do modo como estas determinam seu próprio questionamento, até que alcance o ponto de um questionar que é antes uma atitude existencial, um questionamento do qual ele não é mais autor, "um rendez-vous de questões e pontos de interrogação", onde não é claro "Quem de nós aqui é Édipo? Quem a Esfinge?" (JGB/BM 1, KSA 5.15).

Embora não tenhamos adentrado toda a obra, parece como se atingíssemos algum tipo de clímax. Vários traços sugerem que Nietzsche alcança aqui - por volta de sua experiência-Zaratustra sua última e adequada questão. Daqui em diante vemos muito menos questões retóricas e muito mais questões abertas às quais o autor mesmo também não tem resposta. Isso se sustenta particularmente pelo que ele indica como a questão final ou mais difícil: "a última questão sobre as condições de vida tem sido posta aqui, e confrontamos o primeiro esforço para responder a essa questão pela experiência." (FW/GC 110, KSA 3.471) Essa experiência não é um evento de uma-única-vez depois do qual a resposta ainda pode ser dada. Ela consiste no modo como a vida será vivida a partir de então. Noutras palavras: a última questão é uma questão prática, uma questão que pode ser respondida apenas na prática de uma vida, uma questão cujo assunto nunca pode estar terminado, a qual tem que ser dada cada um por si próprio e nunca pode ser dada por ninguém mais. Recordamo-nos da extrema singularidade desses últimos prefácios, e, em alguma medida, de todos os últimos escritos de Nietzsche.

A questão que finalmente é descoberta é a própria tarefa de alguém. No prefácio ao segundo volume de Menschliches, Allzumenschliches, Nietzsche escreve sobre "o caminho para "mim mesmo", para minha tarefa. Aquele algo oculto e imperioso para o qual ainda não temos nome até que ele finalmente prove ser nossa tarefa" (MA/HH II Prefácio 4, KSA 2.373). Se é verdade, como 
alguns têm sugerido, que o trabalho de um filósofo pode ser resumido em uma questão, então para Nietzsche ela seria essa "tarefa": viver "experimentalmente" e estar "permitido a (alguém) se oferecer à aventura" (MA/HH I Prefácio 4, KSA 2.18); seria este "ideal" com o qual "o verdadeiro ponto de interrogação é posto" (FW/GC 382, KSA 3.637): a questão que antes citei de fröhliche Wissenschaft: Em que medida a verdade pode suportar a incorporação? Eis a questão; eis a experiência" (FW/GC 110, KSA 3.471).

Nesse período, em que Nietzsche descobre sua própria questão, ele menciona algumas vezes que somente agora, subsequentemente, reconhece ou descobre a unidade de seus escritos: "que todos os meus escritos (...) têm algo que (...) os une" (MA/HH I 1 Prefácio, KSA 2.13); "nossas ideias (...) crescem fora de nós com a necessidade com a qual uma árvore dá frutos" (GM/GM Prefácio 2 , KSA 5.248). Isso só poderia ser descoberto a este ponto, no qual descobre sua própria questão, a questão a qual seus escritos já atestam mas que ele mesmo ainda não sabia. A questão para a qual a obra de Nietzsche (se podemos falar aqui de uma resposta) é uma questão que só está sendo descoberta no curso dessa obra.

\subsection{Uma filosofia e sua questão}

Isso me traz à minha conclusão final, com a qual retorno à questão do início de meu artigo: por que a questão à qual o texto dá uma resposta não está simplesmente no início desse texto? A razão é que até mesmo o autor descobre sua questão somente através do texto com o qual ele lhe dá a resposta. É claro que há ou ao menos pode haver uma questão no início de um texto, mas essa questão geralmente não é a questão que realmente importa. A questão que está no início está apenas no início de uma questão. No início o autor ainda pensa que sabe o que está perguntando, mas somente no processo de tentar responder àquela questão ele se meterá em dificuldades, isto é, ele atingirá o embaraço que Platão quer dizer 
na passagem que Heidegger cita no início de Sein und Zeit, a qual diz que o que antes pensávamos que sabíamos, agora se tornou uma questão para nós. A questão que está no início de um texto é o início de uma jornada na qual o autor busca pelo que o move. É exatamente como o que Ricoeur escreve sobre o ser humano, a quem define como "uma história em busca de seu narrador"5. $\mathrm{O}$ que o autor enfim descobre como sua questão não é uma questão arbitrária, em vez da qual ele poderia ter escolhido uma outra. É a questão que ele é, mais do que a que ele coloca. Mihi quaestio factus sum, como St. Augustine escreveu6 .

Apenas num sentido muito restrito a filosofia começa com uma questão. Seria mais correto dizer que ela tenta chegar a uma questão. "O Caso Nietzsche" mostra como isso pode acontecer, a saber, se e somente se um pensador reporta seu pensamento a si mesmo e o torna "existencial". Somente então "o verdadeiro ponto de interrogação é colocado (...), o destino da alma muda, (...) a tragédia começa." (FW/GC 382, KSA 3.637).

\begin{abstract}
When Nietzsche is called a radical philosopher, it is (among other reasons) because he claims to put into question what other thinkers take for granted. In the article I concentrate on the way in which Nietzsche asks his questions, and how his questions (and the vocabulary which he uses to express his questions) develop through his writings. The article points out how Nietzsche gradually discovers his proper question and how this search reaches it climax around 1886. This proper question turns out to be a practical or existential one: "To what extent can truth endure incorporation?" (FW/GC 110 KSA 3.471).

Keywords: question - task - Nietzsche's development
\end{abstract}

5 RICOEUR, P., "Life: a story in search of a narrator". In: DOESER, M.C.; KRAAY, J.N. (orgs.). Facts and Values. Dordrecht, Nijhoff, 1986.

6 AUGUSTINUS, A. Confessionum Libri XIII. Zwolle (Tjeenk Willink) 1960, X.50, p.164. 
Van Tongeren, $\mathrm{P}$.

\section{referências bibliográficas:}

AUGUSTINUS, A. Confessionum Libri XIII. Zwolle (Tjeenk Willink) 1960, X.50.

GADAMER, H.-G., Wahrheit und Methode. Grundzüge einer philosophischen Hermeneutik.

Tübingen: Mohr, 1975.

KANT, I. Logik. Leipzig: Meiner, 1904.

KANT, I. Kritik der reinen Vernunft. Leipzig: Meiner, 2010.

RICOEUR, P., "Life: a story in search of a narrator". In: DOESER, M.C.; KRAAY, J.N. (orgs.). Facts and Values. Dordrecht, Nijhoff, 1986.

Artigo recebido em 17/05/2011.

Artigo aceito para publicação em 20/06/2011.

70 I cadernos Nietzsche 31, 2012 